Review

\title{
Techniques of restoring swallowing mechanisms in the treatment of patients with head and neck cancer: postoperative pain relief, plastic surgery and diet
}

\author{
Anna A. Kushta, Sergey M. Shuvalov \\ National Pirogov Memorial Medical University, Vinnytsia, Ukraine \\ Received 10 July 2020, Revised 26 October 2020, Accepted 1 December 2020
}

(C) 2020, Kushta A.A., Shuvalov S.M.

C 2020, Russian Open Medical Journal

\begin{abstract}
Objective - to review available publications and identify unresolved issues in assessing the functional state of the oral cavity and pharynx, along with swallowing disorders in oncopathology of head and neck, depending on the treatment method. The paper discusses the problems of the extent of surgical interventions and their relationship with the possibility of maintaining the act of swallowing, and contemporary understanding of the swallowing mechanism in normal and pathological conditions. Studies on postoperative pain management and feeding techniques of cancer patients are described.

Conclusion - The mechanisms of impaired swallowing after surgery and chemoradiotherapy have been analyzed. For the first time, the mechanisms of damage to swallowing have been analyzed, and the ways of overcoming pathological conditions, such as dysphagia and pain, were substantiated, with topographic and anatomical details. The perspectives of resolving the issue of nutritional status restoration were outlined.
\end{abstract}

Keywords: swallowing, dysphagia, nutrition, reconstructive surgery, pain relief.

Cite as Kushta AA, Shuvalov SM. Techniques of restoring swallowing mechanisms in the treatment of patients with head and neck cancer: postoperative pain relief, plastic surgery and diet. Russian Open Medical Journal 2020; 9: e0416.

Correspondence to Anna A. Kushta. E-mail: dr anna9@ukr.net.

Tumors of head and neck constitute a significant group of malignant neoplasms characterized by a progressive increase in morbidity. According to the data, published in 2015 by the Global Burden of Disease Cancer Collaboration, over 600 thousand new cases of head and neck cancer were registered worldwide in 2013, while the mortality rate only in cases of mouth and pharynx lesions exceeded 300 thousand people [1]. Worldwide estimates show that oral cancer is one of the most common cancers in the world: it falls into the top ten of cancer categories. For example, cancer of the oral cavity and oropharynx occupy the eighth place among all localizations, which corresponds to $2.5 \%$ of all cancer cases [2, 3]. According to the Age-Standardized Rater (USA), oral cancer occurred in $5.8 \%$ of men and $2.3 \%$ of women per 100,000 population in 2015. Malignant tumors of the oral cavity are usually considered in conjunction with lesions of the lips and oropharynx $[4,5]$. There are also significant geographical differences in tumor incidence, where Ukraine occupies an intermediate place [5-7]. According to the National Cancer Registry of Ukraine, in 2019, head and neck tumors occupied up to $20 \%$ of all oncopathology. Most often people are diagnosed with oral cancer, which constitutes 9.6 cases per 100 thousand population, laryngeal cancer (5.7 cases), lip cancer ( 4.1 cases), and pharyngeal cancer (4.2 cases) [8]. The incidence of head and neck cancer is growing steadily and is characterized by high aggressiveness. Despite the fact that these are tumors of visual localization, the majority of people (over $70 \%$ ) among newly spotted patients with squamous cell carcinoma of the head and neck are diagnosed with common forms of the disease, which are characterized by a significant tumor size and its spread to adjacent structures; $43 \%$ of them have regional, and $10 \%$ have distant, metastases $[9,10]$. Mortality up to a year from the date of diagnosis is $52.2 \%$ for oral cancer, $38.4 \%$ for laryngeal cancer, $12.9 \%$ for pharyngeal cancer, and $6.8 \%$ for lip cancer [11]. Currently, the treatment of head and neck tumors requires a multidisciplinary approach, involving surgeons, radiation specialists and chemotherapists. Despite modern advances in the field of radiation and chemotherapeutic treatment, in the treatment of tumors of this localization, the surgical method occupies an essential place, which, in turn, brings up a number of problematic issues. The first issue is related to the fact that there is no unified protocol for the treatment of neoplasms of this localization in the world (and in Ukraine). The second issue involves inaccessible topographic and anatomical location of the tumor. The third issue includes significant frequencies of local recurrences, metastases, functional disorders, concomitant pathologies, and mortality $[12,13]$.

This review paper is based on materials collected from multiple databases (PubMed, SCOPUS, Web of Science, Google Scholar), libraries, personal experience, and original observations on the issue of swallowing disorders.

The objective of our study was generalization of literaturebased data and identification of unresolved issues in assessing the functional state of the oral cavity and pharynx, as well as 
swallowing disorders in head and neck cancer patients versus the treatment method.

Our article discusses the problems of the extent of surgical interventions and their relationship with the possibility of maintaining the act of swallowing, and contemporary understanding of the swallowing mechanism in normal and pathological conditions. Studies on postoperative pain management and feeding techniques of cancer patients are described.

Surgical treatment of head and neck tumors usually results in damage to one or more of the neuro-muscular swallowing complexes that provide the oral (preparatory) or pharyngeal phase. If the tumor is located in the anterior part of the oral cavity, and resection is necessary, but there is the possibility of maintaining nervous system control and reconstruction of the defect, then this fact allows increasing the movement of the residual tongue, which in turn would lead to better function. The more the tongue is bonded with its anterior to the bottom of the mouth or restricted on the side, the more severe the swallowing disorder would be. The tongue is responsible for controlling food during chewing and moving the bolus posteriorly to initiate swallowing. Tongue movement is a part of the stimulus to induce the pharyngeal phase of swallowing: it plays an important role in generating pressure in the oral and pharyngeal regions. Thus, joining the pharyngeal swallowing, as well as in the oral phase, the tongue, in the course of its lateral movements, reduces the need for intense chewing, controls food in the oral cavity and initiates the swallowing process [14, 15].

The doctor, when planning surgical treatment, must always know the exact, reasonable extent of resection and, accordingly, the reliable nature of the consequent reconstruction. These two factors, generally, provide all needed information to predict, or to determine, the exact nature of the swallowing problems, which a patient could experience in the postoperative period. When the tumor is located in the back of the mouth and oropharynx (the tonsils or the root of the tongue), surgical treatment would usually cause more severe swallowing problems, as opposed to when it is located in the anterior region. The area of the posterior third of the mouth and the root of the tongue is the region between the oral and pharyngeal phases of swallowing. Any treatment directed at this area may affect the mobility of the tongue at the oral stages of swallowing, the occurrence of the swallowing reflex (which occurs mainly in the area of the tongue root and tonsils) and pharyngeal motility, because this process also includes the upper pharyngeal constrictor, fixed laterally to the mandible and the root of the tongue [17]. The root of the tongue plays an important role in propelling the bolus through the oropharynx as well, since it contributes to the formation of pressure in the oropharynx.

Surgical reconstruction, which creates the greatest range of motion for the root and body of the tongue, would result in better control of the tongue during swallowing. But the patient could still experience some delay in the onset of the pharyngeal stage of swallowing and some degree of reduced pharyngeal peristalsis. Swallowing can improve the onset of pharyngeal swallowing, but a decline in pharyngeal motility is usually a significant factor. In turn, the result of such reduced motility of the pharyngeal muscles is ineffective swallowing, with food debris remaining contained in the oropharynx. There is a constant risk of aspiration if the patient inhales uncontrollably while swallowing. To prevent this complication, such patients usually cough repeatedly when eating [18].

Then the second phase of swallowing begins: pharyngeal phase of peristaltic waves. It begins in the upper constrictor and successively moves through the middle to the lower constrictor. When peristalsis is reduced or interrupted, there is a retention of food in the valleculae of the tongue, or on the walls of the pharynx until the pear-shaped sinuses. The peristaltic waves of the pharynx are intended to remove any residual food, following the bolus. Surgical intervention in the pharyngeal wall reduces the possibility of pharyngeal contraction. At greater resection volume, more food remains in the pharynx. When large portions of the pharynx are resected, peristalsis can be so severely reduced that the muscular apparatus cannot move food at all. In addition, a decrease in the motility of the pharynx is associated with a number of surgical operations, performed on the lateral walls of the pharynx, which may contribute to fixation of the larynx with scar tissue, so that the larynx does not rise enough when swallowing, as a result of which the epiglottis cannot approach the upper part of the larynx and aryepiglottic folds $[14,20]$.

Epiglottic protection is not the main protection of the respiratory tract, although it significantly prevents the penetration of food into the vestibule of the larynx. There are several theories regarding the mechanisms that promote epipharyngeal closure during swallowing [14]. The first theory states that the epiglottis is closed by direct muscle tension, specifically in the aryepiglottic folds. The second hypothesis indicates that bolus travels over the body and the root of the tongue, then flips over the epiglottis and pushes it down. The third - and most widespread - explanation presumes that epiglottis is closed by the forces of the posterior part of the tongue when larynx is raised high $[14,15,16]$. The epiglottis root is fixed to the thyroid cartilage. Therefore, when epiglottis folds, the tongue moves backward, and the larynx rises during the swallowing. This hypothesis is supported by the fact that, in patients with a smaller height of the larynx rise, the epiglottis movement is significantly reduced.

When the larynx does not rise sufficiently, and the epiglottis is more upright during swallowing, the peristalsis of the pharynx cannot clear residual food around the epiglottis and the laryngeal vestibule. Since, as a result of surgical interventions, the larynx is lower than it normally would be in the course of swallowing, this leads to retention and ingestion of food in the respiratory tract. This residual food around the laryngeal vestibule is easily inhaled by the patient after swallowing, when the airways are opened in the usual anatomical and physiological way. Any damage to the walls of the pharynx or to the external tissues of the neck may limit the rise of the larynx, causing scarring $[14,17,20]$.

In general, swallowing is a complex physiological mechanism. Most of the time, the pharynx performs other functions, besides swallowing, and only for a few seconds turns into a tract for swallowing food. In the process of swallowing, neuroreflex control of breathing is especially important. The issue of a swallowing mechanism was discussed already back in the nineteenth century. For example, F. Magendie (1817) and most authors of that time considered swallowing a peristaltic process. Later, H. Kronecker, S. Melter, and Falk $(1880,1883)$ presented the act of swallowing as a piston-like process [20]. Currently, it is generally accepted that both mechanisms take place at different phases of swallowing. During the spontaneous phase, food is ready to be swallowed, compressed and rolled under the pressure of the tongue 
posteriorly against the palate. Then, the bolus is pushed into the throat by the force of the tongue. From this point on, swallowing becomes automatic and cannot be stopped.

During the pharyngeal stage, the food bolus is pushed posteriorly; it stimulates the area of tactile receptors along the entire open surface of the pharynx, and specifically the tonsillar hairs, as a result of which impulses from them pass along the sensitive branches of the trigeminal and glossopharyngeal nerves to the swallowing center in the medulla oblongata, and at its command, a series of automatic contractions of the pharyngeal muscles starts. The soft palate is pulled up, closing the entrance to the choanae, thereby preventing food from being thrown into the nasal cavity. The palatine arches converge medially, forming a sagittal fissure, through which food passes into the hypopharynx. The gap formed in this way delays the passage of large food objects. This stage of swallowing lasts about one second, but large objects are held back and do not pass. The vocal cords of the larynx come together tightly, and the epiglottis moves posteriorly over the superior opening of the larynx.

Both of these effects prevent food from entering the trachea. The convergence of the vocal cords is especially important, while the epiglottis helps preventing food from getting onto the vocal cords. Epiglottis removal would not result in serious swallowing problems, but damage to the vocal cords can lead to suffocation, meaning that without the epiglottis, the risk of respiratory failure increases. Simultaneously, both the larynx and the pharynx are pulled up and anteriorly by the muscles, attached to the hyoid bone and lifting the pharynx. At the same time, the lower pharyngeal sphincter around the entrance to the esophagus, preventing the passage of air into it during inhalation, is relaxed, thus allowing food to pass.

Raising the larynx upwards removes it from the main flow of food, which is an additional factor in protecting the trachea. At a time, when the larynx is raised and the lower pharyngeal sphincter is relaxed, superior pharyngeal constrictor muscle is compressed, which contributes to the formation of a fast peristaltic wave passing down the pharyngeal muscles into the esophagus (A.C. Guyton 1971). Thus, the mechanism of the pharyngeal stage of swallowing consists of two interrelated effects: the trachea is closed while the esophagus is open.

During surgical interventions in the area of the oropharynx, volumetric defects of the pharynx are formed, as well as the defects of ligamentous-muscular apparatus, which ensures the rise and closure of the larynx. In operated patients, when trying to swallow food, the laryngopharyngeal complex deviates sharply towards the intact side, as a result of which swallowing becomes impossible. When planning an operation in patients with oropharyngeal cancer, a possible postoperative defect should be evaluated from both anatomical and physiological perspectives $[14,20]$. Surgical reconstruction or preservation of anatomical structures can significantly increase or decrease such functional consequences [21-24]. However, the methods of plastic and reconstructive surgery are rarely used due to their complexity6 even though most defects, arising after surgical removal of the tumor, should be eliminated immediately after the tumor removal [20].

Currently, the following types of reconstructive surgery are used: plastic surgery with a free skin flap [25], regional skin, combined musculocutaneous, arterialized flaps with an axial vascular pattern (deltopectoral), free microsurgical from distant body parts, and musculocutaneous flap of the subcutaneous neck muscle $[20,27,31,45]$. At the same time, free arterialized complex flaps from distant body parts are also actively used worldwide by employing microsurgical procedures [25-30].

In connection with the extent of surgical interventions and difficulties of postoperative closure of defects, chemoradiation therapy is of great importance. However, despite the fact that this method is considered conservative, the complications, associated with it, are no less severe [31-33]. In addition, with a significant prevalence of the tumor process, radiation is used as one of the key stages of combined and complex treatment [34]. The choice of a treatment method should take into account both its effectiveness and possible complications. The evolution of modern conservative treatment methods, such as radiation therapy and chemotherapy, could significantly improve their direct antitumor effect, but is accompanied by an increased risk of complications, leading to a reduction in the quality of life in patients, and sometimes to severe disability or even death [35-37].

There is also a small number studies on the effects of oral, pharyngeal, and laryngeal radiation therapy on swallowing function. The immediate and long-term effects of radiation therapy on oral tissue and salivary glands have been well documented [38]. Immediate effects during therapy include irritation, mucositis, and edema. Long-term effects include xerostomia, tissue devascularization, and jaw necrosis. Toothache may also affect chewing performance. The effect of radiation is observed, such as augmented fibrosis of the tongue and masticatory muscles, as well as an increase in the frequency of caries. The influence of changes in the tissues of the oral cavity and salivation on swallowing remains unresolved problem, but probably increased fibrosis reduces the range of the tongue motion, thereby leading to the swallowing pathology [39, 40].

There are some late signs of radiation therapy causing longterm effects on swallowing, starting six months after it. E.g., in the study by O. Ekberg and G. Nylander (1983), 125 patients received radiotherapy. Their condition was examined one year or more after completion of radiation therapy. In these patients, significant changes in pharyngeal motility were observed, probably associated with a decrease in flexibility of the pharyngeal constrictors due to increased fibrosis.

Due to the decreased peristalsis in patients, there was a retention of food residue in the pharynx after swallowing and a tendency to inhale this residue into the respiratory tract after swallowing. The decreased peristalsis of the pharynx was quite serious, which impeded free passage of any food, except for liquid, through the pharynx and into the esophagus. The level of the critical dose, at which these permanent and long-term effects affect the neuromuscular structures to a greater extent, requires further study [41]. With radiation therapy, dryness and stomatitis of the oral cavity usually occur. They constitute a substantial problem that has not been completely resolved. Recognized methods of wetting and pain relief are not very effective [42-44].

However, combined treatment with radiation therapy at initial stages can be used, which was first applied by V.M. Zykov (1913). According to E.G. Matyakin and A.A. Uvarov (1988), P.P. Kumar et al (2004), and J. Bernier et al (2007), in conditions of regular processes of the oral cavity with an ulcerative-infiltrative neoplasm growth, accompanied by pain and disruption of nutritional process, at the first stage of treatment, radiation therapy, followed by surgical intervention, is indicated. In 1960s-1970s, there were 
reports on the possibility and advisability of combined tumor treatment of the tongue root, and it was concluded that preoperative radiation therapy is more appropriate for cancer of the oral cavity and oropharynx [45]. Still, there are practically no recommendations for a combined treatment method with planned surgical intervention for cancer of the anterior palatine arches. In its turn, preoperative radiation therapy under conditions of tumor intoxication and dysphagia leads to early radiation reactions with an exacerbation of pain, and as a result, it is not always possible to complete the first treatment stage. Two-year disease-free survival in this group of patients was $65.3 \%$ [45]. Therefore, such conditions require high-quality pain relief and even tube feeding [46].

Assessment of the depth of swallowing disorders has a number of difficulties due to lack of objective control methods. The degree of impaired swallowing is evaluated primarily on the patient's subjective perception: it hurts or it does not; can or cannot swallow; what consistency of the food it is possible to swallow, etc. There are also clinical research methods: palate inspection at rest and during phonation; determination of palatine and pharyngeal reflexes; swallowing test. However, the implementation of these techniques in operated patients is quite difficult, due to the pain of the postoperative wound, limitation of mouth opening, and tube feeding. Besides, there are instrumental methods for studying the act of swallowing: video fluoroscopic swallowing exam and transnasal endoscopy. However, the application of these methods is limited due to the complexity of these techniques and limited possibilities of their use in dynamics.

Although the least traumatic and most common method for examining the act of swallowing is the ultrasound technique, the methods for evaluating the results of ultrasound research are not sufficiently developed, because oncologists at the departments of head and neck neoplasms are not proficient in ultrasound techniques, whereas ultrasound examination specialists at polyclinics are not able to perceive the complexity and extent of operations performed by surgeons. Also, the specificity of the anatomical relationships among the structures, involved in the act of swallowing, is a daunting task for ultrasound diagnostics physicians; hence, the method of ultrasound identification of the muscles of the maxillofacial region has not yet been developed. Thus, the top optimal option in resolving this issue, in our opinion, is a combination of knowledge of anatomical formations and skills of ultrasound examination by the same physician - for example, by the maxillofacial surgeon at the department of head and neck tumors. Moreover, in well-known guidelines for ultrasound diagnostics, there is usually no section dealing with the maxillofacial region [47-49].

B-mode ultrasound imaging visualizes the genioglossus, geniohyoid, mylohyoid and digastric muscles. To describe the entire neuromuscular complex during ultrasound examination, which takes part in the act of chewing and swallowing, it is necessary to review the anatomical and physiological data and their systematization. Therefore, we have proposed the following parameters: geniohyoid distance; longitudinal study of the suprahyoid muscle group; transverse study of the suprahyoid muscle group; studies in the lateral projection of the digastric muscle anterior belly; determination of the muscle contraction amplitude on the right and on the left, which makes it possible to compare their synchronicity and contraction force (patent application for invention No. a201911764).
Also, we now describe in more detail the extent of defects, where the anatomical and physiological data on muscle groups and organs, corresponding to the stages of food bolus formation and swallowing, are the basis for assessing the postoperative defect. E.g., we systematized the anatomical and physiological structures, depending on the sequence of the act of chewing and swallowing. The muscles that participate in the act of biting, mastication and chewing include the anterior belly of the digastric muscle, the mylohyoid, masseter and temporal muscles, as well as lateral and medial pterygoid muscles, which are innervated by the mandibular branch of the trigeminal nerve. The muscles that take part in lifting the root of the tongue up and shortening it, thus preparing the food bolus for pushing into the laryngopharynx outside the pharyngeal epiglottis fold are posterior belly of the digastric muscle, stylohyoid, and hyoglossus. Innervation is carried out by the facial nerve, which provides slow, regulated muscle contraction. The third arch includes the muscles of the larynx and pharynx. Here, a spontaneous stage of swallowing occurs, an uncontrolled passage of food into the larynx and esophagus. Innervation here is done by the glossopharyngeal nerve [16, 20].

The knowledge of this neuromuscular apparatus with functions is extremely important when planning surgical interventions and anticipating possible disorders in the formation of a food bolus and swallowing.

In addition, there are nutritional problems in cancer patients with pathology of the oral cavity and oropharynx, because recommendations for completely balanced and nutritious diet have not yet been developed. We consider the founders of the socalled therapeutic nutrition N.I. Pirogov (1854), who was the first to propose a cup for feeding patients with injuries of the maxillofacial region, and I.S. Rubinov (1958) with his technique for assessing the effectiveness of chewing, and graduated cups for feeding the patients. The patients, even while on tube feeding in the postoperative period, continue to lose weight. That is why Yu.K. Sizrantsev and Yu.I. Travnikov (1983) suggested for patients, who underwent radiation therapy and chemotherapy in the postoperative period, to use energy-rich food substitutes (which they named 'enpits') that played a crucial role in increasing the body resistance due to the production of $T$ and $B$ lymphocytes. But even today, the issue of nutrition for cancer patients with pathology of the maxillofacial region remains relevant and requires further study and development of nutrition schemes.

There have been a very few reports on pain relief in such patients in the postoperative period to facilitate swallowing. Thus, we proposed the method of prolonged blockade of the trigeminal nerve branches at the oval and round holes in cancer patients in the postoperative period [50]. Yet solely the anesthesia of the trigeminal nerve mandibular branch is not sufficient for painless swallowing, since it is necessary to take into account the innervation of the muscles, ensuring the lifting of the tongue root upward and pushing the bolus into the laryngopharynx. Without this neuromuscular complex anesthesia, the act of swallowing would remain difficult, and even impossible in some cases.

\section{Discussion}

Despite some approaches to the issue of impaired swallowing and methods of its correction, an integrated approach is still lacking. Therefore, future clinical and experimental studies should focus on elucidating the mechanisms of impaired swallowing and the degrees of dysphagia and aphagia in cancer patients, as well as 
on developing a method for managing patients in the postoperative period with maintaining adequate pain relief and nutritional status. It is also necessary to improve the methods of diagnosing the mechanisms of swallowing disorders via refining the interpretation of ultrasound images of operated areas.

\section{Conclusion}

The mechanisms of impaired swallowing after surgery and chemoradiotherapy have been analyzed. For the first time, the mechanisms of damage to swallowing have been analyzed, and the ways of overcoming pathological conditions, such as dysphagia and pain, were substantiated, with topographic and anatomical details. The perspectives of resolving the issue of nutritional status restoration were outlined.

\section{Conflict of interest}

The authors declare that there is no conflict of interest.

\section{References}

1. Global Burden of Disease Cancer Collaboration, Fitzmaurice C, Dicker D, Pain A, Hamavid H, Moradi-Lakeh M, Maclntyre MF, et al. The Global Burden of Cancer 2013. JAMA Oncol 2015; 1(4): 505-527. https://doi.org/10.1001/jamaoncol.2015.0735.

2. Cancer Incidence in Five Continents Vol. X. Forman D, Bray F, Brewster DH, Mbalawa C, Kohler B, Piñeros M, et al, eds. Lyon, France: International Agency for Research on Cancer. 2014; 1365 p. https://ci5.iarc.fr/cl5l-x/old/vol10/Cl5vol10.pdf.

3. Bray F, Ferlay J, Soerjomataram I, Siegel RL, Torre LA, Jemal A. Global cancer statistics 2018: GLOBOCAN estimates of incidence and mortality worldwide for 36 cancers in 185 countries. CA Cancer J Clin 2018; 68(6): 394-424. https://doi.org/10.3322/caac.21492.

4. Global Cancer Observatory: Cancer Today. Ferlay J, Ervik M, Lam F, Colombet M, Mery L, Piñeros M, et al, eds. Lyon, France: International Agency for Research on Cancer. 2020. https://gco.iarc.fr/today.

5. National Cancer Institute. The Surveillance, Epidemiology, and End Results Program. 2020. https://seer.cancer.gov

6. ECIS - European Cancer Information System. https://ecis.jrc.ec.europa.eu/.

7. The Global Oral Cancer Forum. http://globaloralcancerforum.org/

8. Fedorenko ZP, Michailovich YoYo, Goulak LO, Gorokh YeL, Ryzhov AYu, Soumkina OV, et al. Cancer in Ukraine 2017-2018: Incidence, mortality, activities of oncological service. Bulletin of National Cancer Registry of Ukraine. Vol. 20. Kyiv, Ukraine: NationaL Cancer Institute of Ukraine, 2019; 82 p. http://ncru.inf.ua/publications/BULL 20/index e.htm

9. Lydiatt WM, Patel SG, O'Sullivan B, Brandwein MS, Ridge JA, Migliacci $J C$, et al. Head and neck cancers - major changes in the American Joint Committee on cancer eighth edition cancer staging manual. CA Cancer J Clin 2017; 67(2): 122-137. https://doi.org/10.3322/caac.21389.

10. Tirelli G, Gatto A, Boscolo Nata F, Bussani R, Piccinato A, et al. Prognosis of oral cancer: a comparison of the staging systems given in the 7th and 8th editions of the American Joint Committee on cancer staging manual. Br J Oral Maxillofac Surg 2018; 56(1):8-13. https://doi.org/10.1016/j.bjoms.2017.11.009.

11. Wiegand S, Zimmermann A, Wilhelm T, Werner JA. Survival after distant metastasis in head and neck cancer. Anticancer Res 2015; 35(10): 5499-5502. https://pubmed.ncbi.nlm.nih.gov/26408715/.

12. Maresso K C, Tsai K Y, Brown P H, Szabo E, Lippman S, Hawk E T. Molecular cancer prevention: current status and future directions. $C A$ Cancer J Clin 2015; 65(5): 345-383. https://doi.org/10.3322/caac.21287.
13. Brahme NN, Szabo E. Cancer prevention in the era of precision oncology. Clin Pharmacol Ther 2017; 101(5): 575-577. https://doi.org/10.1002/cpt.566.

14. Head and Neck Oncology: Clinical Management Hardcover. Kagan R, Miles J, eds. Riverside, USA: Pergamon Press. 1989; 176 p.

15. Henderson JM Pathophysiology of the Digestive System. Moscow, Russia: BINOM. 2019; 272 p. Russian.

16. Textbook of Gastroenterology. Yamada T, Alpers DH, Kalloo AN, Kaplowitz N, Owyang C, Powell DW, eds. 5th Ed. Oxford, United Kingdom: Blackwell Publishing. 2009; 3712 p. Ltd. https://doi.org/10.1002/9781444303254

17. Trifiletti DM, Smith A, Mitra N, Grover S, Lukens JN, Cohen RB, et al. Beyond positive margins and extracapsular extension: evaluating the utilization and clinical impact of postoperative chemoradiotherapy in resected locally advanced head and neck cancer. J Clin Oncol 2017 35(14): 1550-1560. https://doi.org/10.1200/ico.2016.68.2336.

18. Valdez JA, Brennan MT. Impact of oral cancer on quality of life. Dent Clin $N \quad$ Am 2018; 62(1): 143-154 https://doi.org/10.1016/i.cden.2017.09.001.

19. Shaw RJ, Holsinger FC, Paleri V, Evans M, Tudur-Smith C, Ferris RL. Surgical trials in head and neck oncology: Renaissance and revolution? Head Neck 2015; 37(7): 927-930. https://doi.org/10.1002/hed.23846.

20. Shuvalov SM. Selected works on maxillofacial surgery. Vinnytsia, Ukraine: Vinobltypography. 2018; 264 p. Russian. Ukrainian.

21. Leiser Y, Barak M, Ghantous Y, Yehudai N, Abu El-Naaj I. Indications for elective tracheostomy in reconstructive surgery in patients with oral cancer. J Craniofac Surg 2017; 28(1): e18-e22. https://doi.org/10.1097/scs.0000000000003168.

22. O'Connell JE, Bajwa MS, Schache AG, Shaw RJ. Head and neck reconstruction with free flaps based on the thoracodorsal system. Ora Oncol 2017; 75: 46-53. https://doi.org/10.1016/j.oraloncology.2017.10.019.

23. Brown JS, Barry $C$, Ho M, Shaw R. A new classification for mandibular defects after oncological resection. Lancet Oncol 2016; 17(1): e23-e30. https://doi.org/10.1016/s1470-2045(15)00310-1.

24. Butterworth CJ, Rogers SN. The zygomatic implant perforated (ZIP) flap: a new technique for combined surgical reconstruction and rapid fixed dental rehabilitation following low-level maxillectomy. Int $J$ Implant Dent 2017; 3(1): 37. https://doi.org/10.1186/s40729-0170100-8.

25. Habib M, Murgasen J, Gao K, Ashford B, Shannon K, Ebrahimi A, et al. Contralateral neck failure in lateralized oral squamous cell carcinoma. ANZ J Surg 2016; 86(3): 188-192. https://doi.org/10.1111/ans.13206.

26. Bell BR, Andersen P, Fernandes R. Oral, Head and Neck Oncology and Reconstructive Surgery. Elsevier. 2018; 968 p. https://www.elsevier.com/books/oral-head-and-neck-oncology-andreconstructive-surgery/bell/978-0-323-26568-3.

27. Sokolov VM, Stavitsky SO, Akhmerov VD, Avetikov DS, Buhanchenko OP. Plastic and Reconstructive Surgery. Avetikov DS, ed. Poltava, Ukraine: ASMI. 2013; 404 p. Ukrainian. http://elib.umsa.edu.ua/handle/umsa/5651.

28. Galich SP, Reznikov AV, Lysenko SI. Reconstruction of the lower jaw using composite tissue complexes. Reconstructive Surgery 2011; (1): 52-54. Russian. http://health-ua.com/pics/pdf/ZU 2011 Hirurg 1/52 54.pdf.

29. Galich SP, Druk NF, Povstyanoy NE. Replacement of post-burn and post-traumatic defects in head and neck area with composite tissue complexes. Annals of plastic, reconstructive and aesthetic surgery 2002; (1): 37-38. Russian

30. Malanchuk VO. Surgical dentistry and slit-facial surgery. Vol. 1. Kyiv, Ukraine: Logos, 2011; 672 p. Ukrainian. https://uacmfs.com/publications/books/272-khirurgichnastomatologiya-ta-shchelepno-litseva-khirurgiya-tom-1

31. Kravets OV, Protsik VS, Khlinin OV. Plastic removal of defects of the oral cavity bottom by the skin-muscle flap of the subcutaneous muscle 
of the neck. Clinical Oncology 2017; (3(27)): 32-34. Ukrainian. https://www.clinicaloncology.com.ua/article/19738/plastichneusunennya-defektiv-dna-porozhnini-rota-shkirno-m-yazovim-klaptempidshkirnogo-m-yaza-shii.

32. Vissink A, van Luijk P, Langendijk JA, Coppes RP. Current ideas to reduce or salvage radiation damage to salivary glands. Oral Dis 2015; 21(1): e1-e10. https://doi.org/10.1111/odi.12222.

33. Riley P, Glenny AM, Hua F, Worthington HV. Pharmacological interventions for preventing dry mouth and salivary gland dysfunction following radiotherapy. Cochrane Database Syst Rev 2017; 7(7): CD012744. https://doi.org/10.1002/14651858.cd012744.

34. Kamstra JI, van Leeuwen M, Roodenburg JLN, Dijkstra PU. Exercise therapy for trismus secondary to head and neck cancer: a systematic review. Head Neck 2017; 39(11): 2352-2362. https://doi.org/10.1002/hed.24859.

35. Bur AM, Lin A, Weinstein GS. Adjuvant radiotherapy for early head and neck squamous cell carcinoma with perineural invasion: a systematic review. Head Neck 2016; 38 Suppl 1: E2350-E2357. https://doi.org/10.1002/hed.24295.

36. Kang HS, Roh JL, Lee SW, Kim SB, Choi SH, Nam SY, et al. Noncancerrelated health events and mortality in head and neck cancer patients after definitive radiotherapy. A Prospective Study. Medicine (Baltimore) 2016; 95(19): e3403. https://doi.org/10.1097/md.0000000000003403.

37. Owosho AA, Tsai CJ, Lee RS, Freymiller H, Kadempour A, Varthis S, et. al. The prevalence and risk factors associated with osteoradionecrosis of the jaw in oral and oropharyngeal cancer patients treated with intensity-modulated radiation therapy (IMRT): The Memorial Sloan Kettering Cancer Center experience. Oral Oncol 2017; 64: 44-51. https://doi.org/10.1016/i.oraloncology.2016.11.015.

38. Sultan A, Hanna GJ, Margalit DN, Chau N, Goguen LA, Marty FM, et. al. The use of hyperbaric oxygen for the prevention and management of osteoradionecrosis of the jaw: A Dana-Farber/Brigham and Women's Cancer Center multidisciplinary guideline. Oncologist 2017; 22(3): 343350. https://doi.org/10.1634/theoncologist.2016-0298.

39. De Felice $F$, de Vincentiis $M$, Luzzi V, Magliulo $G$, Tombolini $M$, Ruoppolo $\mathrm{G}$, et al. Late radiation-associated dysphagia in head and neck cancer patients: evidence, research and management. Oral Oncol 2018; $\quad 77$ 125-130. https://doi.org/10.1016/j.oraloncology.2017.12.021.

40. Sroussi HY, Epstein JB, Bensadoun RJ, Saunders DP, Lalla RV, Migliorati $\mathrm{CA}$, et al. Common oral complications of head and neck cancer radiation therapy: mucositis, infections, saliva change, fibrosis, sensory dysfunctions, dental caries, periodontal disease, and osteoradionecrosis. Cancer Med 2017; 6(12): 2918-2931. https://doi.org/10.1002/cam4.1221.

41. PDQ Supportive and Palliative Care Editorial Board. Oral Complications of Chemotherapy and Head/Neck Radiation (PDQ $\left.{ }^{\circledR}\right)$ : Health Professional Version. 2016 Dec 16. In: PDQ Cancer Information Summaries [Internet]. Bethesda (MD): National Cancer Institute (US); 2002. https://pubmed.ncbi.nlm.nih.gov/26389320/.

42. Tam M, Wu SP, Gerber NK, Lee A, Schreiber D, Givi B, et al. The impact of adjuvant chemoradiotherapy timing on survival of head and neck cancers. Laryngoscope 2018; 128(10): 2326-2332. https://doi.org/10.1002/lary.27152.

43. Santos MA, Guinot JL, Tortajada MI, Santamaria P, Campo V, Oliver L, et al. High-dose-rate interstitial brachytherapy boost in inoperable locally advanced tongue carcinoma. Brachytherapy 2017; 16(6): 12131218. https://doi.org/10.1016/i.brachy.2017.07.006.

44. Cocks H, Ah-See K, Capel M, Taylor P. Palliative and supportive care in head and neck cancer: United Kingdom National Multidisciplinary Guidelines. J Laryngol Otol 2016; 130(S2): S198-S207. https://doi.org/10.1017/s0022215116000633.

45. Galay 00. Optimization of surgical methods for the treatment of muscle-growth cancers of the mucous of the mouth and the oral part of the pharynx. DSc dissertation thesis. 2012; 34 p. Ukrainian.
46. Lee MS, Nelson AM, Thompson LM, Donovan KA. Supportive care needs of oral cancer survivors: prevalence and correlates. Oral Oncol 2016; 53: 85-90. https://doi.org/10.1016/i.oraloncology.2015.11.007.

47. A Practical Guide to Ultrasound Diagnostics. General Ultrasound Diagnostics. Mitkov VV, ed. 3rd edition. Moscow, Russia: VIDAR, 2019; 756 p. Russian. http://vidar.ru/Product.asp?prdCode=0168p.

48. Loshchilov VI. Ultrasound Technologies in Oncosurgery. Moscow, Russia: MSTU Publishing House. 1999; 118 p. Russian.

49. Hill K, Miller E, Bamber J. Ultrasound in Medicine: Physical Basis. Moscow, Russia: Fizmatlit. 2008; 544 p. Russian.

50. Gafarov HO. A new method of palliative analgesic therapy in maxillofacial surgery. PhD thesis. Samara, Russia. 2015; 22 p. Russian. http://medical-diss.com/medicina/novyy-metod-palliativnoyprotivobolevoy-terapii-v-chelyustno-litsevoy-hirurgii.

\section{Authors:}

Anna A. Kushta - MD, PhD, Assistant Professor, Department of Oral and Maxillofacial Surgery, Pirogov National Medical University of Vinnytsia, Vinnytsia, Ukraine. https://orcid.org/0000-0001-8994-2560.

Sergey M. Shuvalov - MD, DSc, Professor, Chair of the Department of Oral and Maxillofacial Surgery, Pirogov National Medical University of Vinnytsia, Vinnytsia, Ukraine. https://orcid.org/0000-0001-5052-680x. 